\title{
LA OBRA LEXICOGRÁFICA DE MANUEL HURTADO DE MENDOZA: SUS DICCIONARIOS ENCICLOPÉDICOS DE MEDICINA"
}

\author{
Bertha M. Gutiérrez Rodilla
}

Facultad de Medicina, Universidad de Salamanca

\begin{abstract}
RESUMEN
La figura de Manuel Hurtado de Mendoza ya se ha analizado suficientemente en relación con sus aportaciones a la anatomía española de la primera mitad del siglo XIX o a la introducción en España de algunas novedades europeas. Sin embargo, todavía queda por estudiar buena parte de su obra, como ocurre con los diccionarios de medicina que compuso, dos enciclopédicos y uno terminológico. De los dos primeros nos ocupamos en este trabajo, en el que ponderaremos su importancia en un siglo en que la lexicografía especializada despegó en Europa, mientras que en España no alcanzó más que un tímido desarrollo.
\end{abstract}

PALABRAS CLAVE: Historia de la metalexicografía especializada. Lexicografía médica. Diccionarios enciclopédicos. Siglo XIX. Manuel Hurtado de Mendoza.

\section{MANUEL HURTADO DE MENDOZA'S LEXICOGRAPHIC WORKS - HIS ENCYCLOPEDIC MEDICAL DICTIONARIES}

\begin{abstract}
The figure of Manuel Hurtado de Mendoza has been sufficiently analyzed in connection with his contributions to Spanish anatomy during the first half of the 19th century or to the introduction of some European innovations in Spain. However, there is still much of his work to be studied, such as the medical dictionaries he wrote, two encyclopedic and one terminological. We deal with the first two in this essay, where we will speak highly of his significance in an age in which specialized lexicography took off in Europe, while it did not reach but a timid development in Spain.
\end{abstract}

KEY WORDS: History of Specialized Metalexicography. Medical Lexicography. Encyclopedic Dictionaries. XIXth. Century. Manuel Hurtado de Mendoza.

* La investigación necesaria para llevar a cabo este trabajo se ha financiado con la ayuda del Ministerio de Educación y Ciencia FFI2011-23200 al proyecto «Lexicografía y Ciencia: otras fuentes para el estudio histórico del léxico especializado y análisis de las voces que contienen». 


\section{INTRODUCCIÓN}

La figura del médico Manuel Hurtado de Mendoza (Villagarcía de Campos, Palencia/Valladolid, 1785-Madrid, 1849) ya se ha estudiado y ponderado lo suficiente en relación con sus aportaciones al ámbito de la anatomía española de la primera mitad del siglo XIX (Aréchaga Martínez, 1977, pp. 31101; Riera Palmero, 1970) o con la introducción en nuestro país de algunas novedades europeas, particularmente el brusismo (Miqueo, 1989 y 1995), lo que nos ha permitido conocer diversos detalles de su vida y de su trayectoria profesional. Así, por ejemplo, sabemos que este médico castellano, que se formó inicialmente en el Colegio de Cirugía de San Carlos de Madrid y que militó en el bando que apoyaba a Francia durante la Guerra de la Independencia, en 1814 se exilió a París, por entonces a la vanguardia de la renovación médica europea. En dicha ciudad, además de seguir relacionándose con médicos españoles afrancesados como Tomás García Suelto entre otros, completó su formación en diversos hospitales junto a figuras como Esquirol, Pinel o Récamier, pero sobre todo el controvertido Broussais, a quien había conocido en España durante la Guerra y de cuyo sistema médico - el brusismo - se convertiría en infatigable defensor y difusor. Allí desplegó una notable actividad científica, que se refleja en los trabajos que publicó en diversas revistas francesas, como los dedicados al tratamiento de las fiebres intermitentes (1815), al «cólico gangrenoso» (1817) y, especialmente, al uso terapéutico de la raíz de ratania (1816), que se traduciría al alemán (López Piñero, 1983a, p. 464)ํ.

En 1820, tras regresar de su exilio parisino y conseguir el grado de doctor en Huesca, se instaló en Madrid, donde inició una etapa muy productiva, que se beneficiaría de la protección que tuvieron los afrancesados durante la década ominosa: publicó un elevado número de libros, así como 20 volúmenes de la revista Décadas Médico-Quirúrgicas [y farmacéuticas] (enero 1821diciembre 1828), fundada por él. Entre esos libros publicados, pertenecientes a diferentes ámbitos, unos eran originales y otros traducidos. Siendo los primeros muy importantes, tanto o más lo fueron los traducidos, pues con ellos, este «Jourdan español» — como lo calificó Chinchilla² — contribuyó de modo decisivo a la difusión de la nueva medicina europea y a la renovación de los

1 García Ramos (1980) ofrece algún otro detalle sobre la vida de Hurtado.

2 «Este profesor es tal vez el que más ha contribuido con sus traducciones á propagar en España los conocimientos que en medicina habia en los paises estrangeros. [...] ha sido el Jourdam español; pues asi como este ha enriquecido la literatura médica francesa con las traducciones de obras alemanas, asi aquel ha enriquecido la nuestra con las traducciones francesas» (Chinchilla y Piqueras, 1841-1846, IV, p. 567). 
saberes médicos en España en la primera mitad de la centuria ${ }^{3}$. De su obra original, destaca sin duda su Tratado elemental completo de anatomía (18291830), conformado por tres volúmenes dedicados a la anatomía descriptiva, topográfica y patológica. Sus contribuciones al ámbito histológico y anatómico son muy valiosas, pero más lo es - a decir de Riera (Riera Palmero, 1970, p. 221) - su libro dedicado enteramente a la anatomía patológica, pues no solo se trata de uno de los primeros textos que se ocupan de tal materia de forma exhaustiva, sino que significa la introducción definitiva de la mentalidad anatomoclínica en España y el inicio de su desarrollo de forma sistemática en nuestro país. La relación de textos que incluye al final de dicho tratado pone de manifiesto el excelente conocimiento que tenía de las principales obras del momento, aun las recién publicadas, en contraste evidente con lo que para esa misma época mostraban otros médicos españoles, muy desfasados con respecto a la medicina europea (Riera Palmero, 1970, p. 200).

Por otro lado, como adelantábamos, dirigió las Décadas MédicoQuirúrgicas [y farmacéuticas] —llamadas Décadas de Medicina y Cirugía práctica, desde 1824, una revista que a pesar de no contar ni con apoyos institucionales ni con la ayuda de un grupo habitual de colaboradores, actuó como el vehículo de difusión de las novedades europeas más importante de su época (Miqueo, 1989, p. 101) . Esto, junto a las traducciones a que acabamos de referirnos, y su participación desde 1836 como colaborador habitual, bajo la dirección de Mariano Delgrás, del Boletín de Medicina, Cirujía y Farmacia, le convierten en una de las figuras más sobresalientes del panorama médico español de la primera mitad del siglo decimonónico:

el publicista médico más destacado de esta época española, tanto en lo referente a obras originales como a traducciones y uno de los pocos médicos españoles de estos años conocidos y traducidos en Francia y Alemania (López Piñero, 1964, p. 73 , nota 61$)$.

Queda todavía por analizar, sin embargo, buena parte de la extensa obra de este prolífico autor. Entre otros textos, sus diccionarios de medicina, que fue-

3 Entre sus traducciones se encuentran su versión del manual anatómico de J. P. Maygrier (1820) o de dos de los tratados de Broussais: el de la fisiología aplicada a la patología (1827) y el de la irritación y la locura (1828). López Piñero (1983a, p. 464) ofrece las referencias completas de estas obras.

4 La revista se hizo eco particularmente del brusismo, hasta tal punto, que terminó convirtiéndose en su portavoz en España, sistema al que permaneció fiel aun después de que se rechazara en otros países (Miqueo, 1989 y 1995). 
ron realmente notables, en un siglo en que la lexicografía especializada despegó en varios lugares de Europa, mientras que en España no alcanzó más que un tímido progreso.

\section{LA LEXICOGRAFÍA MÉDICA EN EL SIGLO XIX}

Según lo acabamos de señalar, en el siglo XIX se consagra la lexicografía especializada, en concreto la médica, en países como Francia, Alemania o Reino Unido, donde se desarrolló extraordinariamente un tipo de repertorio lexicográfico: el diccionario enciclopédico, en el que se intentaba recopilar el saber procedente de diversas áreas de la medicina, tomado de diferentes libros e, incluso, de algunas revistas o periódicos. En estos diccionarios enciclopédicos - denominados por algunos de sus autores simplemente como «Diccionarios»- lo importante eran las «cosas», los conceptos, particularmente los más novedosos y no las palabras o los términos. Esto explica que las voces que allegaban no fueran todas las que podrían tener cabida en un diccionario terminológico, sino más bien aquellas cuyo contenido hubiera experimentado un cambio importante en los últimos tiempos. El afán de exhaustividad de los que intervenían en estas empresas lexicográficas, que solían ser varios, hacía que la información que se ofrecía habitualmente fuera muy amplia, a veces de varias páginas para una única entrada, lo que determinaba que estos compendios necesitaran de gran cantidad de volúmenes para poder acoger todo lo que se pretendía incluir en ellos.

Como lo estamos tratando de mostrar, estas enciclopedias eran en definitiva manuales médicos actualizados, dispuestos según el orden alfabético, mediante los que se pretendía ofrecer al profesional la más completa revisión posible de aquello que hubiera sufrido cambios notables en tiempos recientes. Intentaban facilitar a sus lectores el poder estar más o menos «al día» sobre las últimas novedades, sin tener que comprar y leer todas las obras donde se sucedían, de forma imparable, los últimos descubrimientos o las nuevas teorías. En este sentido, no es casual que el fenómeno del enciclopedismo médico surgiera en la Francia de la segunda mitad del siglo XVIII y alcanzara ese importante auge de que hablamos en las primeras décadas del XIX — periodo dorado de la medicina francesa-, para ir extendiéndose desde allí a otros lugares, como Gran Bretaña, Alemania o Italia. También llegó hasta la península Ibérica, aunque lo hizo con cierto retraso y de un modo bastante atemperado. Para convencerse de ello basta con pensar que durante el siglo XIX vieron la luz en Francia más de cincuenta repertorios enciclopédicos, contando 
únicamente con primeras ediciones. Unos valores muy similares a los registrados en Alemania y a los que se acercó bastante el Reino Unido. Los de España, sin embargo, no llegaron ni a la mitad: se publicaron 15 compendios de este estilo, 4 de factura española y 11 resultado de la traducción, valores desnudos también, sin contar con reimpresiones o segundas ediciones ${ }^{5}$.

En todo caso, en la segunda mitad de la centuria los diccionarios enciclopédicos a que nos estamos refiriendo, que hasta entonces se habían ocupado de la medicina en general, dejaron de tener sentido y poco a poco fueron desapareciendo. Por un lado, porque para entonces las enciclopedias globales de medicina suponían un modo pesado y muy costoso de luchar contra la obsolescencia médica frente a las ágiles y versátiles publicaciones periódicas, que al igual que estos diccionarios tenían entre sus principales objetivos el dar cuenta de todas las innovaciones que se iban produciendo: era más cómodo y más barato sacar los diferentes números de las revistas que seguir embarcados en unas enciclopedias con numerosos volúmenes que, cuando aparecían en el mercado, ya estaban desactualizadas. Por otro lado, la medicina había iniciado su inexorable viaje hacia la fragmentación en especialidades, por lo que a partir de entonces los repertorios generales de medicina empezaron a dejar paso a los diccionarios enciclopédicos especializados: higiene, anatomía, pero sobre todo, terapéutica, fueron las áreas mejor representadas. Esta fiebre del enciclopedismo especializado tampoco duró demasiado - hasta principios del siglo $\mathrm{XX}$-, pues también en la última parte del XIX habían comenzado su andadura las revistas por especialidades, contra las que de ninguna manera podían luchar las enciclopedias especializadas.

A diferencia de los anteriores, los diccionarios terminológicos - conocidos generalmente por entonces como «Vocabularios»-, tenían como objeto de atención principal las palabras, los términos. Eso explica que en ellos las entradas no fueran demasiado prolijas, sino más bien cortas, con definiciones precisas, por lo que este tipo de repertorio no solía contar con más de un volumen, dos a lo sumo. Lo que pretendían sus autores no era dar cuenta de los avances de la medicina, sino fijar el significado de los términos, en un momento de gran preocupación por el lenguaje médico en aquellos dominios lingüísticos más sensibles a la invasión neológica, procedentes de las lenguas de los países que llevaban la batuta en la renovación de la medicina. En esa situación de debilidad se encontraba precisamente el español ya al inicio de la centuria. La situación no mejoró en el transcurso de la misma, dado que los continuos avances de la medicina conllevaban un cambio ininterrumpido so-

\footnotetext{
5 Puede encontrarse más información en Gutiérrez Rodilla (1999).
} 
bre los tecnicismos médicos, por lo que la avalancha de neologismos y de extranjerismos se intensificó.

Las razones anteriores justifican el peso que en el conjunto de los diccionarios médicos españoles del XIX alcanzaron los terminológicos, que supusieron el $16 \%$ del total de los repertorios lexicográficos publicados; algo que no consiguieron en modo alguno en Francia, donde el predominio de la lexicografía enciclopédica fue absoluto y totalmente excepcionales los repertorios terminológicos (Gutiérrez Rodilla, 2011, pp. 121-122). Que el fenómeno lexicográfico francés, como el alemán, dentro del ámbito médico, fuera eminentemente enciclopédico respondía a una situación originada por un excelente cultivo de la medicina con sucesión de doctrinas y descubrimientos de toda índole; algo que en España no tuvo lugar o, al menos, no a ese nivel. Faltando aquí ese tipo de vida científica, no es de extrañar que tanto o más que las enciclopedias médicas necesitáramos los diccionarios terminológicos, en los que se fijaran los significados de un sin fin de nuevos términos que iban apareciendo por doquier. La lengua francesa de la medicina - o la alemana- todavía no parecía correr peligro, por lo que esa función de los repertorios terminológicos no la sentían los médicos de Francia o Alemania como algo primordial. De ahí que esta fórmula lexicográfica tuviera escaso desarrollo en esos países. Mientras que aquí, sobre todo si consideramos la actividad continua de traducción de obras médicas a nuestra lengua, se justifica fácilmente.

Pero no solo fue el distinto nivel de la medicina francesa o alemana respecto a la española lo que condicionó el diferente desarrollo de la lexicografía médica en nuestro país, ya fuera esta enciclopédica o terminológica. Hubo otro hecho fundamental, que tuvo que ver con el escaso o nulo apoyo institucional para sacar adelante cualquier proyecto de esta índole. Nuestras aventuras lexicográficas del ámbito médico no contaron con una infraestructura adecuada a la magnitud de la tarea, ni consiguieron tampoco el apoyo de las instituciones, academias o sociedades que podrían haber hecho que prosperaran; apoyo, que resultó ser fundamental en Francia (Didier, 1996, p. 9). De ahí que nuestros diccionarios originales fueran en general obras individuales, sacadas adelante solo gracias al esfuerzo y tesón de sus autores, tras enfrentarse a multitud de dificultades para conseguirlo.

Entre tales autores destacó uno por encima de los demás, tanto por la calidad de su obra y el entusiasmo y esfuerzo con que la acometió, como por la amplitud de la misma: Manuel Hurtado de Mendoza, quien compuso tres compendios lexicográficos del total de 25 que aparecieron publicados en el siglo decimonónico en nuestro país, dirigidos específicamente a los médicos, es decir, sin contar con los destinados a la divulgación. Esto no solo supone 
que el mismo autor se implicó en la confección del 12\% de tales obras, lo que constituye un hecho insólito, sino que si consideramos el número de volúmenes y de páginas que tuvieron sus textos y lo absolutamente laborioso que es elaborar un diccionario, aceptaremos sin reparo lo excepcional de la figura de Hurtado en la historia de la metalexicografía médica española. Sus tres repertorios pertenecen respectivamente a las tres categorías lexicográficas que hemos indicado: un diccionario enciclopédico de medicina general; uno, también enciclopédico, especializado, en este caso en terapéutica; y un vocabulario terminológico. Nos ocupamos a continuación de los dos enciclopédicos, dejando el terminológico, por motivos de espacio, para otra ocasión.

\section{EL DICCIONARIO DE MEDICINA Y CIRUGÍA DE MANUEL HURTADO DE MENDOZA}

Los cuatro volúmenes que conforman el Diccionario de Medicina y Cirugía, aparecieron publicados entre 1820 y 1823 (Hurtado de Mendoza y Martínez Caballero, 1820-1823). A esta obra se la suele conocer como Suplemento al diccionario de Ballano, aunque en realidad fuera un repertorio independiente y muy distinto de aquel al que supuestamente suplementaba, como deduce fácilmente cualquiera que los haya comparado. El cirujano madrileño Antonio de Ballano había publicado entre 1805 y 1807 el que fuera el primero de los diccionarios enciclopédicos aparecidos en España (Ballano, 1805-1807)6, del que se hizo una reimpresión - y no segunda edición, como se suele afirmar- en 1815-1817 (Ballano, 1815-1817). En él se ocupaba, a lo largo de siete volúmenes, de la medicina y la cirugía en un sentido amplio, sin olvidarse de los principales nombres de los cultivadores de la profesión a lo largo de la historia. Dada la acogida que tuvo su compendio, el propio Ballano prometió que contaría con un suplemento que actualizara su contenido, para cuya consecución él mismo inició los trabajos pertinentes, pero la enfermedad y la muerte le impidieron cumplir su promesa. Ante esa situación, otro médico madrileño buen amigo de Ballano, Tomás García Suelto ${ }^{7}$, que ya le había ayudado en la confección del primer diccionario, asumió el compromiso en mayo de 1816. Casualmente, también se lo llevó la muerte en septiembre de ese mismo año, por lo que tampoco pudo culminar el trabajo, del que solo

6 Gutiérrez Rodilla (1999, pp. 35-41) ofrece más datos sobre este diccionario y su autor.

7 El propio Hurtado escribe una reseña biográfica sobre este autor, a su muerte en París (Hurtado de Mendoza, 1816). López Piñero (1992, p. 207 y 1983b) recoge más información sobre García Suelto. 
elaboró cinco artículos, como veremos enseguida. Y así fue, finalmente, como Manuel Hurtado de Mendoza se hizo cargo del famoso suplemento, al que dedicó siete años de su vida, según él mismo lo revela al finalizar el mismo .

De tal suplemento, ya tenía elaborados dos volúmenes en marzo de 1817, en que solicita el permiso para imprimirlos en París. Como se recoge en las páginas que anteceden al diccionario propiamente dicho, para conceder tal permiso se solicitó un informe a «profesores de mérito de aquella capital, y que conociesen el idioma español» (Hurtado de Mendoza y Martínez Caballero, 1820-1823, «Advertencia», I, s.p.), que fueron finalmente Larrey, Fournier y Ribes, en cuyo informe afirman:

Hemos observado que esta obra está redactada con toda exactitud, que contiene una excelente doctrina médico-quirúrgica; que muchos de sus artículos estan compuestos con un tino muy notable y una vasta erudicion [...]; que contiene una bibliografía completa; y que en fin tanto relativamente a la erudicion como á la ciencia y al estilo, esta obra es de las que hacen honor a la lengua y a la nacion española (Hurtado de Mendoza y Martínez Caballero, 1820-1823, «Copia y traducción del informe original», I, s.p.).

A pesar de tan elogiosas palabras, los volúmenes elaborados por Hurtado no llegaron a publicarse como estaban: por la misma época, Celedonio Martínez Caballero ${ }^{9}$ - sobrino de Antonio de Ballano, con el que había colaborado en la elaboración del primer diccionario - se vió en la obligación de concluir la obra de su tío, para lo que recogió algunos materiales durante sus estancias en Londres y en París y redactó unos pocos artículos. Al saber que Hurtado tenía intención de publicar los volúmenes del suplemento, se entrevistó con él en la capital francesa y acordaron fusionar sus respectivos trabajos, añadiendo a los volúmenes de Hurtado los artículos de Martínez Caballero y los pocos que llegó a componer García Suelto. Todo lo cual retrasó la aparición de la obra y, a la larga, perjudicó a Hurtado, no solo por tener que compartir autoría con alguien cuyo trabajo no superó el $0.5 \%$ del total del diccionario, sino también porque ese retraso haría que su publicación coincidiera en el tiempo con la de otro diccionario enciclopédico, lo que le trajo algunos problemas, como veremos más adelante.

8 Desde mayo de 1816 hasta mayo de 1823. (Hurtado de Mendoza, 1820-1823, «Tabla ó indice alfabético de las materias y articulos que sirven de complemento y esplicacion al Diccionario de Ballano y á este suplemento», III (2), p. 949).

9 Médico madrileño, afrancesado, que tras una estancia de más de dos años en Londres y varios meses en París, regresó a España. 


\subsection{Estructura y contenido del Diccionario}

El suplemento que finalmente vió la luz constaba de tres tomos, divididos en cuatro volúmenes: los dos primeros tomos, que comprenden las letras A-D y E-M respectivamente, se redactaron en París. El tercer tomo, que firma exclusivamente Hurtado de Mendoza, se escribe ya en España, entre 1820 y 1823. Los dos volúmenes que lo integran se ocupan, el primero de ellos, de las letras $\mathrm{N}$ a la mitad de la $\mathrm{S}$, y el segundo, desde la otra mitad de la S, a la Z. Entre las páginas 949 y 1241 del segundo volumen del tercer tomo se incluye un último suplemento - los suplementos a que están condenadas siempre las obras enciclopédicas, que nunca terminan de estar completas-, con todo aquello que pudiera haber cambiado desde que en 1816 se inició la confección del Diccionario hasta 1823 que es cuando se logra acabarlo (Hurtado de Mendoza, 1820-1823, «Tabla ó indice alfabético de las materias y articulos...», III (2), p. 949).

Ya hemos apuntado que, a pesar del nombre que lleva y por el que suele conocérsele, el famoso Suplemento es en realidad un nuevo diccionario, que si en varias ocasiones remite al de Ballano, en muchas otras suprime o corrige lo consignado en él. En relación con este punto, en la «Advertencia» con que se abre el primer tomo, sus autores dejan constancia de que para que su repertorio pueda ser útil también a aquellos que no posean el de Ballano, lo han elaborado sin conexion con la información que se ofrece en él. Y que se han hecho dos propósitos fundamentales: incluir numerosos artículos que faltaban en el texto del médico madrileño; y reformular otros, que aunque sí se encontraban allí, estaban necesitados de que se revisaran, dados los cambios experimentados por los saberes médicos desde que se compusieron hasta entonces (Hurtado de Mendoza y Martínez Caballero, 1820-1823, «Advertencia», I, s.p.). Con el fin de que se pueda apreciar la evolución de la medicina desde sus orígenes, prometen insertar siempre que sea posible lo que Hipócrates y los clásicos, pero también otros autores posteriores, creen sobre las diversas materias que vayan analizando. Promesa que mantienen, de forma que son numerosísimos los autores citados, sobre todo contemporáneos y de procedencia francesa, pero también de otras latitudes. El afán de ser exhaustivos en la inclusión de tantas novedades les obliga — continúan advirtiendo en su declaración de intenciones - a confeccionar un texto que constará de tres volúmenes, en lugar de los dos en que pensaban originalmente, por lo que se excusan ante los posibles lectores, si bien están convencidos de que no les defraudarán. De hecho, al final de la obra, en el volumen cuarto de la misma, Hurtado de Mendoza concluye: 
$\mathrm{Si}$ [los profesores del arte de curar] encuentran en ella, como creemos, en términos claros y sencillos, la esposicion sumaria de todo lo que presenta en el dia de nuevo y positivo la ciencia de curar, habremos logrado el objeto que nos hemos propuesto, y al mismo tiempo tendremos la dulce satisfaccion de haber servido á la ciencia que cultivamos con tanto entusiasmo, y á la humanidad (Hurtado de Mendoza, 1820-1823, «Advertencia», III (2), p. VIII).

Los problemas de espacio a que estamos aludiendo les llevaron a realizar un cambio notable respecto a la obra de Ballano, consistente en suprimir la parte histórica, biográfica y bibliográfica que dicha obra allegaba - aunque por un error, permanecieron seis entradas correspondientes a seis autores, cuyo apellido comienza por la letra B - . A cambio, añadieron varios artículos no presentes en aquel, caracterizados con la marca Historia de la Medicina: abuso, academias, archiatro, escuela, galenismo, humorismo, metódico..., más uno de cuatro páginas dedicado por entero a dicha disciplina; artículos, que dejaban entrever otra de las inclinaciones del polifacético Hurtado, quien un cuarto de siglo más tarde publicaría una Historia Crítica de la Medicina (Hurtado de Mendoza, 1845). Igualmente se incluyeron algunas entradas de interés, desde una perspectiva histórico-médica, como geografia médica, dedicada a la importancia del influjo del clima y el suelo sobre el ser humano, su salud y enfermedad, así como sobre lo beneficioso de confeccionar buenas «Geografías médicas». O como metodología médica, cuyas 60 páginas versan sobre cómo debería programarse la formación del futuro profesional de la medicina y los libros que debería estudiar, además de ofrecer una comparación del plan de estudios español con el vigente en Francia. El resto de los diversos artículos coleccionados en esta obra, que pueden venir señalados con alguna de las marcas recogidas en una tabla al comienzo de la misma (anatomía, cirugía, física médica, fisiología, higiene, literatura médica, materia médica, medicina legal, patología, terapéutica, etc.), pertenecen a todas las áreas de la medicina. En este sentido, llama la atención a priori lo bien representada que están la cirugía y los instrumentos de que se sirve, pues no suele ser eso lo más habitual en los repertorios lexicográfico-médicos del pasado, así como la anatomía, ya sea esta descriptiva, fisiológica, patológica o gene$\mathrm{ral}$, de acuerdo con las marcas del diccionario. No sorprende tanto, sin embargo, si recordamos que Hurtado recibió su formación inicial en el Colegio de Cirugía de San Carlos y comenzó trabajando como cirujano antes de marchar a Francia.

En la «Advertencia» inicial avisan de que en su texto se encontrarán los fundamentos de la obra de Broussais, como no podía ser de otra forma, dada 
la adhesión ciega de Hurtado al brusismo, a que ya nos referíamos; los preceptos y observaciones de la medicina práctica de Robert Thomas, lo que tampoco carece de lógica, pues sería precisamente Martínez Caballero quien hiciera la versión española del texto fundamental de este autor (Thomas, 1824); así como lo más interesante, donde corresponda, de lo que ofrece la anatomía patológica que tan fructíferamente «se cultiva en el dia, y que ha proporcionado grandes progresos á la medicina moderna», en consonancia con lo que mencionábamos más atrás sobre el conocimiento que Hurtado poseía de esta materia, de la que sería introductor en España. Y las tres cosas se cumplen, aunque de modo desigual: efectivamente, son numerosas las alusiones a Broussais en innumerables artículos (calentura, debilidad, degeneración, doctrina, fiebre, gastritis, irritación, nosología, progresos del arte de curar, respiración... son solo algunos de ellos); muy frecuentes también las explicaciones anatomopatológicas (por ejemplo, en deformidad, cálculos de la glándula pineal, exceso de partes, fibrosas, fungosas, incrustación, melanose, etc.), además de la propia subentrada Anatomía patológica en la entrada Anatomía. Pero son más bien raras las citas a la obra de Thomas (por ejemplo, en diabetes), lo que se explica por el reducido número de artículos redactados efectivamente por Martínez Caballero, como vamos a ver, que debió ser el único que se apoyó en el autor inglés. En relación con esto que decimos, del total de los artículos, según lo consigna el propio Hurtado en el volumen segundo del tomo tercero, Tomás García Suelto habría elaborado las entradas anatomía patológica, atmósfera marítima, disimuladas (enfermedades), errores en medicina y exhumación ${ }^{10}$. Martínez Caballero, por su parte, habría compuesto las voces alvinas (concreciones), aneurisma, calentura, contagio, diabetes, epidémicas (enfermedades), escarlatina, espina bifida, femur, fungus hematodes, gonorrea, hemorragias (cir.), hidrargiria y ligadura ${ }^{11}$. Y José Pasamán —otro médico español afincado en París en la misma época que Hurtado - sería el responsable de los artículos necroscopia y oído (enfermedades del) ${ }^{12}$. Lo anterior pone de manifiesto de forma incontestable que fue Manuel Hurtado de Mendoza el principal redactor del Suplemento, pues los tres colaboradores mencionados únicamente fueron artífices de una veintena

10 A pesar de lo que señala Hurtado, las iniciales G. S. solo aparecen al finalizar las dos primeras.

11 Las iniciales M. C. acompañan también al artículo afusión.

12 A su vuelta a España y antes de emigrar a Hispanoamérica, donde desarrollaría una actividad médica importantísima, traduciría junto a Lorenzo Sánchez, un Manual de medicina práctica de Nysten (Nysten, 1818). 
del total de artículos incluidos en el repertorio, que solo en su primer tomo allegó 285 .

En esos artículos del primer tomo, que se extienden a lo largo de 501 páginas, la información que se provee alterna entre las definiciones de pocas líneas y las enciclopédicas - que ocupan media página o páginas enteras-, siendo mayoría estas últimas, que en algunos casos, alcanzan las 10, 15 o 20 páginas o incluso más. Los artículos abdomen, aborto, agua, aneurisma, anatomía —on 36 páginas, es el más largo-, calentura, crisis, crónicas, debilidad, digestión y dolor son los más ampliamente tratados. No es muy frecuente encontrar la marca D. de B. (Diccionario de Ballano) y no es habitual que se remita a dicho repertorio, en este primer tomo. Lo que acabamos de señalar va poco a poco cambiando, a medida que avanza la obra. Y así, en el tomo segundo, cada vez son más los artículos de pocas líneas y menos los de larga extensión, aunque todavía estos sean muchos, como estómago, gastritis, hemorragias o intestinos, por ejemplo. Basta para convencerse de este cambio que recogemos con saber que el segundo tomo incluye 866 artículos que ocupan 716 páginas y comparar estos datos con los del tomo primero: si halláramos la media de páginas que le corresponde a cada artículo del primer tomo, esta sería de 1.75 , mientras que en el segundo ya descendería a 0.8 . Un fenómeno que se acentúa todavía más en el tercero, cuyo primer volumen, con 640 páginas, incluye 1383 voces, por lo que la media de páginas por artículo sería de $0.46 . .$. Un tomo tercero que va perdiendo el carácter de enciclopédico, pues la mayoría de las entradas no se extienden más allá de una o dos líneas, aunque siempre existan excepciones: $n e u$ ralgia, nosologia, oído, organología, pectoriloquia, piel, progresos y estado del arte de curar, reproductor, respiración, sanguíneo, sensitivo o sexo, son algunas de ellas, además del artículo reproductor, al que dedica 62 páginas ${ }^{13}$. Al mismo tiempo, las remisiones a la obra de Ballano van siendo cada vez más frecuentes. Y, asimismo, van desapareciendo poco a poco las marcas con las que se caracterizaban todas las voces del primer tomo y buena parte de las del segundo, hasta llegar a ser rarísimo que aparezca alguna en el tercero. Es como si a Hurtado, que por entonces (1820-1823) estaba plenamente inmerso en sacar adelante sus Décadas de Medicina y Cirugía, le pesara cada día más la elaboración del diccionario, que a juzgar por los resultados parece terminó como pudo: la calidad de los volúmenes que componen el tomo tercero se resiente frente a la de los anteriores. Unos volúmenes que además pierden la característica de «enciclopédicos» para casi convertirse en «terminológicos».

13 Parece que este tema le interesaba particularmente, pues como veremos enseguida, tan solo dos años antes había publicado una obra sobre la Generación. 


\subsection{El repertorio de Hurtado y el Diccionario de Ciencias Médicas}

Pero no deberieron ser el hartazgo y el tedio que suponen la confección en solitario de un repertorio enciclopédico de medicina los únicos factores que determinaron las prisas por acabar, el abandono del método seguido sistemáticamente en la elaboración de los primeros volúmenes de la obra y la consiguiente pérdida de calidad en su última parte. Hubo otro hecho que tuvo que influir de forma negativa en el ánimo de Hurtado y en su trabajo, ligado a la aparición en España de otro diccionario enciclopédico de medicina, que venía a competir con el suyo, como ya adelantábamos y como explicaremos enseguida. Desde que comenzara a trabajar en su repertorio, en 1816, Hurtado había estado muy atento a lo que iba apareciendo en los volúmenes del Dictionnaire des Sciences Médicales, elaborado por varios autores y publicado en Francia entre 1812 y 1822 (VV. AA., 1812-1822). Una obra que él valoraba lo suficiente $-\mathrm{y}$ que quizá actuara como acicate para que emprendiera la suya - como para traducir tres de sus artículos, escritos inicialmente por J. J. Virey, y publicarlos como un libro independiente dedicado a la generación (Hurtado de Mendoza, 1821) ${ }^{14}$. Y lo suficiente también como para integrar en su compendio todo lo que encontraba interesante en ese diccionario. Deja constancia de ello desde el principio, en la «Advertencia» con que comienza el primer volumen del repertorio, fechado en la imprenta en 1820, pero que ya estaba redactado, como dijimos, en 1817:

Se encontrará con frecuencia en este Suplemento lo mas interesante del Diccionario de ciencias médicas que se está acabando de publicar en París (Hurtado de Mendoza y Martínez Caballero, 1820-1823, «Advertencia», I, s.p.).

Y en consecuencia con ello, no es infrecuente encontrar referencias al citado diccionario en los artículos tratados. Así, por ejemplo, en aborto, explica que lo que se leerá en él está extractado del Diccionario de Ciencias Médicas; en degeneración, aclara que está sacado del artículo Anatomía patológica de tal repertorio; el artículo debilitación comienza «El Dr. Nacquart, en el diccionario de Ciencias Médicas define esta palabra...»; en eudiometro avisa que quien quiera «noticias tan extensas como exâctas» sobre los diferentes eu-

14 Hubo otro autor, Lorenzo Sánchez, al que acabamos de nombrar en la nota 12 por su traducción junto a Pasamán del Manual de Nysten, que elaboró asímismo una obra a partir de la traducción de varios artículos de este repertorio, en este caso, sobre las fiebres esenciales (Sánchez Núñez, 1819). 
diometros y su utilidad, «puede consultar el artículo Eudiometro del Diccionario francés de Ciencias Médicas»; o el artículo facial termina:

El que desee mayores detalles sobre esta materia, podrá consultar las láminas y el artículo correspondiente del tomo 14 del Diccionario francés de ciencias médicas, del cual nos hemos servido en gran parte para la composición de éste.

Pero, igualmente, lo que echaba de menos en el diccionario francés lo completaba con los artículos o las informaciones que consideraba pertinentes. Actuando de esta manera estaba convencido de ofrecerle al público español el mejor diccionario de medicina que podía encontrar, sin tener que recurrir a los elaborados en otros lugares:

Nos parece que teniendo el Diccionario de Ballano y este suplemento, se tiene el Diccionario frances de Ciencias Médicas, y algo mas; pues los lectores verán, que ademas de hallarse en aquel la esposicion detallada de la nueva doctrina médica, se encuentran otros muchos artículos de que carece este (Hurtado de Mendoza, 1820-1823, «Advertencia», III (2), p. V).

Pasando por alto el hecho de que resulta un poco exagerado que los 60 volúmenes del compendio francés pudieran ser equivalentes a los 11 que sumaban en total los 4 del suplemento más los 7 del Ballano, Hurtado hacía esta declaración ya a punto de culminar su obra, en 1823, con toda intención, pues en 1821 habían comenzado a publicarse los volúmenes de la traducción al español del Dictionnaire des Sciences Médicales... (VV. AA., 1821-1827). Esto para Hurtado no dejaba de ser un «golpe bajo» y una provocación, ya que él había apostado por el camino más difícil: redactar una obra nueva, aunque para ello utilizara los diccionarios existentes hasta el momento entre los que se encontraba su admirado repertorio francés - y aprovechara de ellos toda la información posible. Algo que se ha hecho siempre a lo largo de la historia en la composición de este tipo de repertorios. Pero los intereses de un editor habían puesto en marcha la maquinaria de la publicación de una enciclopedia de medicina en varios volúmenes, la versión española del Diccionario de Ciencias Médicas, por la vía relativamente fácil de la traducción; una versión que venía a competir de lleno con la obra de Hurtado, puesto que en ella había integrado, según lo hemos dicho, todo lo que consideraba más relevante de aquel repertorio. Los propios traductores del diccionario francés eran plenamente conscientes del conflicto de intereses que estaban generando. Solo así se explica la nota que incluyen al principio del cuarto volumen de su diccionario: 
Cuando leimos el anuncio publicado en el tomo II, numero 7 de las Décadas médico-quirúrgicas y farmacéuticas del suplemento al Diccionario de Medicina y Cirugía del profesor Antonio Ballano, por los doctores Don Manuel Hurtado de Mendoza y Don Celedonio Martínez Caballero, no dudamos un momento en presagiar el terrible nublado que descargaría sobre la traducción al Diccionario francés de Ciencias médicas (VV. AA., 1821-1827, «Advertencia á los Sres. Suscriptores del Diccionario de Ciencias Médicas», IV, p. III).

Si los autores de la nota eran sinceros, no se debían haber enterado de la publicación del Suplemento, pues el primer tomo del mismo ya estaba en la calle mucho antes de que se publicara tal anuncio al que aluden y, en todo caso, antes también de que apareciera el primer volumen de la versión española del Diccionario de Ciencias Médicas... Hurtado intentó desquitarse de esta molesta coincidencia editorial en el tiempo con la publicación de una serie de notas en las Décadas Médico-Quirúrgicas... dirigidas contra dicha versión española del repertorio, ya que en su opinión en ella no se encontraba la pretendida actualización de los materiales que pregonaban sus traductores. De este modo se desató una polémica entre ellos y el controvertido Hurtado: aquellos aprovecharon la ocasión para criticar irónica y displicentemente, no ya el Suplemento o las reseñas de las Décadas, sino la figura completa de Hurtado, sus opiniones anticontagionistas y su vinculación al sistema brusista, como lo pone de manifiesto el ejemplo siguiente:

$¡ O$ bien haya la suerte venturosa del profesor [...] Brussais, que nos ha enviado un apóstol que predique y anuncie sus evangelios médicos á todo el mundo médico-quirúrgico español! (VV. AA., 1821-1827, «Advertencia á los Sres. Suscriptores...», IV, p. IV),

lo que no deja de llamar la atención, pues es sorprendente que le reprocharan a Hurtado su afinidad al brusismo los traductores de un diccionario en el que, según la acerba crítica de Déchambre, «la influencia de Broussais se dejaba sentir manifiestamente». Y, cuando este repertorio se resumió y se comercializó como Dictionnaire abrégé, entonces «el brusismo se instaló en él con toda comodidad» (Déchambre y Lereboullet, 1864-1889, I: XV-XVI).

Hurtado, mientras tanto, iba mostrando a través de páginas y páginas de su periódico la sesgada e ignorante versión del Diccionario de Ciencias Médicas que quería venderse en España (Miqueo, 1995, p. 173). El párrafo siguiente, escrito por los traductores del repertorio francés, nos sirve como ilustración del tono de la polémica, así como de la imagen despectiva que querían transmitir del autor del Suplemento: 
Contamos con la generosidad de nuestros retadores, para que nos señalen el sitio, hora y armas con que debemos batirnos, y los unos se defiendan con sus moxas sanguijuelas y pociones gomadas y aromatizadas; y los otros enristrando su guadaña inexorables, den un ejemplo al mundo de su valor y denodado esfuerzo, defendiendo los derechos de la ciencia, y el honor de sus profesores (VV. AA., 18211827, «Advertencia á los Sres. Suscriptores...», IV, p. V) $)^{15}$.

En todo caso, y concluímos así este apartado, ambos repertorios, el Suplemento y la traducción del Diccionario de Ciencias Médicas se encontraron entre los pocos proyectos editoriales de cierta envergadura acometidos en una época en que la pobreza de la edición médica en España fue más que notoria (López Piñero, 1964, pp. 68-69).

\section{EL DICCIONARIO ENCICLOPÉDICO DE TERAPÉUTICA}

Como ya lo adelantamos, fue también Manuel Hurtado de Mendoza el artífice de una de las cuatro enciclopedias de terapéutica, con disposición alfabética, que surgieron en nuestro país durante el siglo decimonónico (Hurtado de Mendoza, 1843). Destaca del resto, no solo por ser la única que se publicó en la primera mitad de ese siglo, sino por ser también la única de origen español, ya que las otras tres llegaron desde Francia y su aparición se concentra entre los años setenta y ochenta de la centuria (Gutiérrez Rodilla, 2011). El interés por la terapéutica responde a que, según nuestro autor, de todas las partes de la medicina, es «una de las mas esenciales, así como tambien la que ha dado materia para el mayor número de escritos» (Hurtado de Mendoza, 1843, «Prólogo», s. p.). Sin embargo, dado el vacío que - en su opinión - se encuentra en muchos de esos escritos, y dada igualmente la dificultad para acceder a todos ellos, por su dispersión, considera útil confeccionar este diccionario, donde se ofrezca una síntesis y una crítica de todo ello.

Hurtado, que ya estaba al final de su vida, y que dejaba tras de sí un cuarto de siglo de enfrentamientos con algunos de sus compañeros de profesión madrileños, temía que su obra desencadenara de nuevo la crítica de estos. Por lo que se cura en salud ya desde la introducción de la misma:

15 No cabe duda de que las moxas sanguijuelas y las pociones gomadas y aromatizadas eran las armas que le concedían a Hurtado frente al valor y denodado esfuerzo que se dejaban para sí mismos en la defensa de los derechos de la ciencia y el honor de sus profesores... 


\begin{abstract}
nuestra intencion es [...] la de reunir y exponer, en cada enfermedad, los medicamentos y preparaciones, simples ó compuestas, que presentan una eficacia conocida [...] y que se encontraban esparcidas acá y acullá en varios autores [...] Aun cuando se nos acuse por algunos de hacer el empirismo, como se nos acusó de conducir el estado de la medicina á proporciones demasiado estrechas cuando introdujimos en España la teoría de la irritacion ó doctrina fisiológica del inmortal Broussais, no por eso dejaremos de persistir en creer que el modo como presentamos los hechos á profesores que continuamente estan luchando con las dificultades de la práctica es el mas justo, racional y provechoso (Hurtado de Mendoza, 1843, «Prólogo», s. p.).
\end{abstract}

Y, si bien su edad no era la más propicia para embarcarse en una iniciativa lexicográfica de esta envergadura — pues ya por entonces rondaba los 60 años-, su afán de recopilación y de difusión de las novedades más notables, en este caso en el ámbito de la terapéutica, le llevó una vez más a lanzarse a la publicación de esta enciclopedia, mediante la que facilitaba un resumen de lo que consideraba tenía mayor interés para aquellos que no contaban con demasiadas facilidades para estar al día en este campo. Continuaba de esta manera la tarea emprendida en 1821 cuando fundó la revista Décadas de Medicina y Cirugía, claramente orientada hacia los profesionales aislados del mundo rural, a través de la que pretendía convertirse en un medio de comunicación de esas novedades para estos profesionales (Miqueo, 1995, p. 173).

El compendio terapéutico de Hurtado se publicó inicialmente en 1843. Y debió contar con cierta aceptación por parte del público, ya que los tres volúmenes que lo integraban se reeditaron cuatro años más tarde, poco antes de su muerte. Algo, que parece indicar que no era del todo cierta la supuesta falta de interés que hacia sus escritos mostrarían sus colegas en la última parte de su vida, como se menciona maliciosamente en una de sus necrológicas:

En vano quiso refugiarse en la literatura porque sus obras empezaron a ser tan poco buscadas como su asistencia ${ }^{16}$.

El primero de esos volúmenes, con 386 páginas, incluye 60 artículos, correspondientes a las letras A (49) y B (11); el segundo, con 488 páginas, 90 artículos pertenecientes a las letras C (54), D (23) y E (13); y el tercero, que

16 Tomamos la cita de López Piñero (1983a, p. 465). Sin embargo, aunque él recoge que hay dos necrológicas de Hurtado de Mendoza -una, firmada por Francisco Méndez Álvaro, en el Boletín de Medicina, Cirugía y Farmacia, 4, 1850: 174 y otra, anónima, en Gaceta Médica, $5,1849,116-$, hemos buscado ambas en tales sitios y no las hemos encontrado ni en los lugares citados, ni tampoco en los números anteriores y posteriores de esas revistas. 
se divide en dos tomos y cuenta con un total de 780 páginas, allega 329 artículos, para las letras E (44), F (19), G (39), H (47), I (18), L (10), M (23), N (9), O (16), P (35), Q (1), R (13), S (22), T (15), U (4) y V (14) ${ }^{17}$. Nos encontramos de nuevo ante un típico diccionario enciclopédico, pues la norma es que las entradas con que cuenta se extiendan a lo largo de unas cuantas páginas - entre 5 y 20, normalmente-, como sucede en almorranas, bocio, clorosis, debilidad, encefalitis, fiebre, gangrena, hemorragia, indigestion, litiasis, menorragia, neuralgia, oftalmía, pulmonía, quemadura, reumatismo, tumor o úlcera, por poner solo un ejemplo de cada letra. Aunque no faltan las que ocupan una sola página, como acedía, antojos, ankiloblefaron o bulimia, o incluso, media, como acrimonia, activo, blenorrea o bradipepsia; así como las que superan esa veintena de páginas, entre las que destacan absceso, con 30; artritis, con 57; y, sobre todo, calentura, con 191.

Para cada término suele ofrecer Hurtado una breve introducción — donde se define, se clasifica y se recogen unas mínimas informaciones generales de tipo clínico o patogénico - y a continuación se centra en los diferentes tratamientos que se pueden aplicar, sus beneficios, limitaciones y contraindicaciones, si fuera el caso. El artículo calentura, que como lo acabamos de señalar es el de mayor extensión de todo el repertorio, constituye el ejemplo más elaborado de esto que decimos: se definen las calenturas, se habla de los diversos tipos de ellas que hay y se pasa revista a los trabajos terapéuticos «modernos» que han ido apareciendo sobre este proceso morboso: «Consideraciones terapéuticas sobre el uso de...»; «De la curación de la calentura por el método del doctor...», «Sobre la propuesta elaborada por... para tratar la calentura», etc. En el análisis que efectúa de todas esas propuestas muestra abiertamente su acuerdo o desacuerdo, fundamentando siempre sus opiniones, para terminar recomendando la opción que considera más adecuada.

Del gran conocimiento de la bibliografía más importante que para cada entidad tenía el médico castellano da buena prueba el elenco de fuentes y autores - franceses, ingleses, alemanes e italianos, fundamentalmente- que aporta en cada caso, de los que proceden las distintas propuestas terapéuticas estudiadas. A veces, incluso, hasta recoge casos clínicos, tomados también de la literatura o estudios y ensayos de tratamientos practicados sobre determinados grupos de pacientes, procedentes en su mayoría de épocas cercanas a la redacción de la obra. Un buen ejemplo lo constituye la entrada afonía, donde

17 En este número total de términos, no contamos las remisiones que se hace a otras voces. En las letras J, K, X y Z, se incluyen algunas entradas, pero no se definen, sino que remiten a otros artículos de la enciclopedia. 
además de citar a Andral, Graves, Bennati, Guenther, Jolly, Lembert, Moreau, Most, Olivier, Piorry, Rosenthal, Thibert, Trousseau y Webster, presenta y analiza detalladamente una memoria clínica de Hirtz, sobre la afonía y la ronquera, publicada en la Gaceta médica de Estrasburgo. No debe creerse que esto que decimos es excepcional, sino que más bien es lo habitual, al menos en los dos primeros volúmenes del repertorio ${ }^{18}$. Así, en la entrada siguiente a afonía, que corresponde a aftas, cita a Bahi, Dewes, Everle, Frank, Grant, Guersent, Huc, Joerg, Kluge, Luttmann, Merrem, Nardo, Rau, Rosen, Schneider, Simon, Starke, Swediaur, Wendt, Weikard y Wolff. En alucinaciones, poco más allá, se refiere a un caso de un enfermo de 3 de diciembre de 1840 -recordemos que esta enciclopedia se publica en 1843 - y a tres observaciones recientes de alucinaciones, publicadas por el Dr. Croisant en el «último número» de la Gaceta de los hospitales. Creemos que con estos ejemplos basta para aceptar sin reservas la familiaridad de Hurtado con la literatura médica que le era contemporánea y con todos los avances y cambios que se estaban produciendo - en esta ocasión en el mundo de la terapéutica- fuera de nuestras fronteras, de los que, una vez más, se hacía eco en su obra, a través de la cuál les daba difusión.

Como en el caso del Suplemento, que compuso 25 años antes, Hurtado debió ir perdiendo fuerza o ganas, a medida que avanzaba en la elaboración de su obra; lo cual tampoco sorprende en una empresa de esta magnitud, llevada a cabo además por una sola persona. Solo así se explica que le dedique un volumen entero a las dos primeras letras del alfabeto, un segundo volumen a las tres siguientes, mientras que en el último volumen, a pesar de sus dos tomos, se ocupe de los términos correspondientes a 16 letras. La diferencia se aprecia claramente al pasar las páginas del diccionario, pues se va observando que cada vez los artículos tienen menor extensión. Y si repitiéramos la prueba que hacíamos con el Suplemento, de dividir el número de artículos incluidos en cada volumen por el número de páginas que tiene ese volumen, comprobaríamos que la media de páginas por artículo es de 6.43 en el primer volumen, 5.42 en el segundo y 2.37 en el tercero, lo que parece confirmar el cansancio de Hurtado o las prisas al final por querer concluir el libro cuanto antes... A pesar de ello, no cayó en la tentación de aprovechar el material del Suplemento para su enciclopedia terapéutica — algo que sí hizo en la confección de su

18 En el último volumen disminuye el número de autores citados, en proporción con la longitud de cada entrada, aunque siguen siendo varios los que se citan, con el fin siempre de apoyar los diferentes tratamientos analizados. Se mantiene, igualmente, el mismo esquema para articular la información ofrecida en cada entrada: definición, tipos, posibilidades terapéuticas. 
vocabulario terminológico, publicado poco antes, en 1840 (Gutiérrez Rodilla, en prensa)-, pues no solo la información que aporta en uno y otro repertorio en las entradas comunes a ambos es diferente, sino que una buena parte de los términos recogidos en la obra de terapéutica no estaban en la de medicina general, lo que incidentalmente da cuenta además de la actualidad de los mismos. En lo que sí coinciden los dos diccionarios es en la notable representación que consiguen en ellos la cirugía y las especialidades quirúrgicas (obstetricia, traumatología...), todavía más acentuada en este de terapéutica: absceso, ankilosis, ascitis, cuerpos estraños, dislocacion, enteritis, escrófulas... Hasta tal punto que en el volumen tercero la inmensa mayoría de las voces que alcanzan más de 10 páginas, son las pertenecientes al ámbito quirúrgico: fistula, fractura, gangrena, herida, hernia, litiasis, parto o peritonitis, entre otras. Es como si, a pesar de haber explorado a lo largo de su existencia buena parte de las diversas áreas de la medicina, como queda patente en sus escritos, su formación inicial y sus primeros pasos profesionales siguieran pesando tantos años después, a punto de concluir su carrera.

\section{A MODO DE CIERRE Y CONCLUSIÓN}

Después de lo recogido en las páginas precedentes no consideramos exagerado ponderar a Manuel Hurtado de Mendoza, con todas sus flaquezas y desaciertos, como una de las figuras más destacadas del panorama lexicográfico médico español del siglo XIX, por no decir la más importante de entre ellas. Un panorama que comparado con el de otras latitudes fue relativamente pobre, pues fueron muy pocos los autores que se adentraran por esta vía. Algo, que realza aún más las aportaciones de Hurtado, redactor de tres repertorios, sacados adelante en solitario y sin ningún apoyo institucional: el primero de nuestros vocabularios terminológicos (Hurtado de Mendoza, 1840), un diccionario enciclopédico de terapéutica —el primero que se publicó en España de tales características - y otro de medicina general. Sobre este último, conocido como Suplemento al Diccionario de Ballano, hemos tratado de establecer lo inadecuado de tal denominación, ya que fue concebido y ejecutado como un diccionario independiente. Por otro lado, también hemos puesto de manifiesto lo improcedente de reconocerle la coautoría de esta obra a Celedonio Martínez Caballero, quien se ocupó tan solo de 14 de los más de 3500 artículos que allega. Esto sin contar con los problemas que le acarreó a Hurtado tener que esperar a conjuntar su obra con los artículos de Martínez Caballero: el retraso en la publicación del Suplemento, que podría haber visto la 
luz en París en 1817, lo que habría evitado la coincidencia con el Diccionario de Ciencias Médicas y ahorrado los inconvenientes derivados de la misma.

Los diccionarios enciclopédicos de Manuel Hurtado de Mendoza son una prueba más de la intensa actividad que desarrolló este «magnífico erudito y probablemente buen clínico» (Aréchaga Martínez, 1977, p. 36) a lo largo de su trayectoria como publicista, difusor y divulgador de lo más importante de la nueva ciencia que iba apareciendo en Europa, fundamentalmente en Francia. No cabe duda de que dedicó sus mejores afanes a compensar el aislamiento científico en que se vio envuelta España, precisamente en la época de mayor desarrollo de esa medicina más allá de los Pirineos, contribuyendo de modo notorio a la renovación de los conocimientos médicos en nuestro país. Lamentablemente para él, sus inclinaciones políticas - especialmente con la delicada posición en la que quedaron a partir de 1834 los antiguos afrancesados, protegidos hasta entonces por Fernando VII-, su escasa inserción en la comunidad médica madrileña, su estilo ciertamente dogmático, incluso arrogante al defender sus ideas, su renuencia a abandonar el brusismo cuando ya todos lo habían hecho y, quizá, el no ser profesor universitario o de los Colegios de Cirugía fueron factores que pesaron en su contra. Tal vez estos factores se aliaron con los recelos y envidias que siempre despertó por su indudable conocimiento de la literatura médica extranjera más reciente y las novedades contenidas en ella y su familiaridad con los autores que firmaban tales novedades y el resultado fue que no consiguiera mayor estimación en vida por parte de sus colegas. Una falta de estimación que seguramente ha contribuido a que tampoco haya obtenido siempre el reconocimiento debido en la historiografía posterior.

\section{BIBLIOGRAFÍA}

Aréchaga Martínez, Juan (1977), La anatomía española de la primera mitad del siglo $X I X$, Granada, Universidad de Granada.

Ballano, Antonio de (1805-1807), Diccionario de Medicina y Cirugía, o Biblioteca manual médico-quirúrgica, 7 vols., Madrid, Imp. Real.

Ballano, Antonio de (1815-1817), Diccionario de Medicina y Cirugia o Biblioteca manual médico-quirúrgica, 7 vols., Madrid, Francisco Martínez Dávila (vols. 1, 4-7), Fuentenebro (vol. 2) y Repullés (vol. 3).

Chinchilla y Piqueras, Anastasio (1841-1846), "Manuel Hurtado de Mendoza". En: Anales históricos de la Medicina en general y biográfico-bibliográficos de la española en particular, 4 vols., Valencia: Imprenta de López y Cía., IV, pp. 567-568. 
Déchambre, Amédée y Lereboullet, Léon (dirs.) (1864-1889), Dictionnaire encyclopédique des sciences médicales, 100 vols., París, Masson.

Didier, Béatrice (1996), Alphabet et raison. La paradoxe des dictionnaires au XVIII siècle, Paris, PUF.

García Ramos, José Antonio (1980), “Sobre la biografía del anatómico vallisoletano Manuel Hurtado de Mendoza", Galicia Clínica, 10, pp. 539-558.

Gutiérrez Rodilla, Bertha M. (1999), La constitución de la lexicografía médica moderna en España, La Coruña, Toxo Soutos.

Gutiérrez Rodilla, Bertha M. (2011), "Cuando querer no es poder: las dificultades para introducir en España los diccionarios médicos franceses del siglo XIX”, Cuadernos de Filología Francesa, 22, pp. 107-122.

Gutiérrez Rodilla, Bertha M. (en prensa), "El Vocabulario terminológico de Manuel Hurtado de Mendoza y el lenguaje médico de la España decimonónica", Revista de Filología Española.

Hurtado de Mendoza, Manuel (1816), Notice biografphique sur le Docteur Thomas Garcia Suelto, París, Mignéret.

Hurtado de Mendoza, Manuel (1821), Tratado histórico y fisiológico completo sobre la generación. Traducción hecha de los tres artículos Generación, Hombre y Mujer del Diccionario francés de Ciencias Médicas, Madrid, Antonio Martínez.

Hurtado de Mendoza, Manuel (1840), Vocabulario médico-quirúrgico, o Diccionario de Medicina y Cirugia, que comprende la etimologia y definicion de todos los terminos usados en estas dos ciencias por los autores antiguos y modernos, Madrid, Boix.

Hurtado de Mendoza, Manuel (1843), Enciclopedia de terapéutica ó tratado de terapéutica especial, médica y quirúrgica, en el cual se exponen por órden alfabético todos los adelantamientos que ha hecho hasta el dia esta parte la mas importante de la ciencia de curar. Coleccion puramente práctica y de una aplicacion inmediata á la cabecera de los enfermos, 3 vols., Madrid, J. Viana Razola.

Hurtado de Mendoza, Manuel (1845), Historia Crítica de la Medicina ó sea Exámen filosófico de los sistemas de la medicina en todas las épocas de su historia, Madrid, M. de Burgos.

Hurtado de Mendoza, Manuel y Martínez Caballero, Celedonio (1820-1823), Diccionario de Medicina y Cirugia o Suplemento al Diccionario de Antonio de Ballano, 3 tomos en 4 vols., Madrid, Viuda de Barco López /Brugada (Tomo 1, 1820, V. de Barco; Tomo 2, 1821, V. de Barco, Tomo 3, 1823, Brugada).

López Piñero, José Ma (1964), "El saber médico en la sociedad española del siglo XIX”. En: López Piñero, José Mª; García Ballester, Luis; Faus Sevilla, Pilar, (eds.), Medicina y Sociedad en la España del siglo XIX, Madrid, Sociedad de Estudios y Publicaciones, pp. 31-108.

López Piñero, José M $M^{a}$ (1983a), "Hurtado de Mendoza, Manuel”. En: López Piñero, José $\mathrm{M}^{\mathrm{a}}$ (dir.), Diccionario histórico de la ciencia moderna en España, 2 vols., Barcelona, Península, I, pp. 463- 465. 
López Piñero, José Ma (1983b), “García Suelto, Tomás”. En: López Piñero, José Ma (dir.), Diccionario histórico de la ciencia moderna en España, 2 vols., Barcelona, Península, I, pp. 384-385.

López Piñero, José Ma (1992), “Las ciencias médicas en la España del siglo XIX”, Ayer, 7, pp. 193-240.

Miqueo, Consuelo (1989), "Estudio de una revista: Décadas Médico-Quirúrgicas (18211828)", Asclepio, 41, pp. 93-130.

Miqueo, Consuelo (1995), "La introducción y difusión del brusismo en España". En: Arquiola, Elvira y Martínez Pérez, José (coords.), Ciencia en expansión. Estudios sobre la difusión de las ideas científicas y médicas en España (s. XVIII-XX), Madrid, Ed. Complutense, pp. 159-180.

Nysten, Pierre -Hubert, Manual de Medicina práctica, escrito en francés por... Traducido al castellano por D. Lorenzo Sánchez Núñez y D. José Pasamán, San Sebastián, I. R. Baroja, 1818.

Riera Palmero, Juan (1970), "La obra anatómica de Hurtado de Mendoza", Cuadernos de Historia de la Medicina Española, 9, pp. 197-229.

Sánchez Núñez, Lorenzo (1819), Diccionario de fiebres esenciales, Madrid, Repullés.

Thomas, Roberto (1824), Tratado de Medicina práctica moderna, 3 vols., trad. desde la quinta edición inglesa por Celedonio Martínez Caballero, Madrid, Fuentenebro.

VV. AA. (1812-1822), Dictionnarie des Sciences Médicales, par une société de Médecins et de Chirurgiens..., M. M. Alard, Alibert, Barbier..., 60 vols., París, Panckouke.

VV. AA. (1821-1827), Diccionario de Ciencias Médicas, por una sociedad de los más célebres profesores de Europa, traducido al castellano por varios facultativos de esta Corte, 39 vols., Madrid, Impr. Calle de la Greda y, desde tomo 5, Mateo Repullés.

Recibido: 1 de abril de 2011

Aceptado: 12 de octubre de 2011 